Research Article

\title{
Synthesis of an Anion-Exchange Membrane Based on Imidazolium-Type Ionic Liquids for a Capacitive Energy Extraction Donnan Potential Device
}

\author{
Young-Seok Kim and Seong-Ho Choi \\ Department of Chemistry, Hannam University, Daejeon 305-811, Republic of Korea \\ Correspondence should be addressed to Seong-Ho Choi; shchoi@hannam.ac.kr
}

Received 19 June 2014; Accepted 31 July 2014; Published 18 September 2014

Academic Editor: Ying Zhou

Copyright (C) 2014 Y.-S. Kim and S.-H. Choi. This is an open access article distributed under the Creative Commons Attribution License, which permits unrestricted use, distribution, and reproduction in any medium, provided the original work is properly cited.

Polymeric anion-exchange membranes (AEMs) were synthesized via the photocopolymerization of a vinyl imidazolium ionic liquid, with 1-butyl-3-(4-vinylbenzyl)imidazolium chloride ([BVBI] $[\mathrm{Cl}])$ as the anion-exchange group and styrene, acrylonitrile, and divinylbenzene as cross-linked agents. The physical, mechanical, and electrochemical properties of the prepared AEMs such as water uptake (\%), swelling degree (\%), ion-exchange capacity ( $\mathrm{mmol} / \mathrm{g})$, thermal stability, tensile strength (Mpa), tensile modulus (Mpa), elongation (\%), and ionic conductivity $(\mathrm{S} / \mathrm{cm})$ were evaluated. The synthesized AEMs were shown to have good physical, mechanical, and electrochemical properties for application of a capacitive energy extraction Donnan potential (CDP) device membrane. The CDP device was fabricated by using the synthesized AEM. The specific capacitance of the CDP device with AEM was determined as $2.53 \mathrm{~F} / \mathrm{g}$ and $3.44 \mathrm{~F} / \mathrm{g}$ by galvanostatic charge/discharge and cyclic voltammetry, respectively. The synthesized AEM with imidazolium ionic liquid can be applied as the CDP device membrane.

\section{Introduction}

Polymeric anion-exchange membranes (AEMs), which have selective anion permeability, were applied to wide range fields such as clean up and decontamination processes. AEMs have been traditionally investigated intensively because of their current and potential applications such as ion-exchangers [1], biomaterials [2], coating [3], and membranes in electrodialysis devices [4-7]. In the past decade, interest in AEMs has been focused on their application toward more demanding uses such as alkaline fuel cells, redox flow batteries, and electrolyzers because of the low overpotential of many electrochemical reactions at high $\mathrm{pH}[8-11]$. Most of studies that have interest in AEMs have been related to the development of materials based on quaternized polymers that contain quaternary ammonium groups as anion exchangers.

On the other hand, a capacitive energy extraction Donnan potential (CDP) device is a piece of equipment that extracts energy from the salinity gradient difference between river and sea water. A CDP device was combined with carbon electrodes and ion-exchange membranes in a supercapacitor flow cell, which has been proposed to have desirable advantages [12]. Sales et al. proposed a characterization methodology of a CDP device with AEM via CDP device performance [13].

Ionic liquids (ILs) have been studied extensively in recent years due to their unique properties. These properties of ILs include being liquid at room temperature and possessing thermal and electrochemical stability because they consist of ions. In addition, ILs also possess low volatility, nonflammability, and high ion conductivity. The excellent ion-exchange capabilities of ILs make them very useful in ion-exchange applications. However, generally ILs cannot be polymerized because they possess no vinyl groups in spite of having unique properties. Therefore, ILs cannot be used to prepare anionexchange membranes.

In this study, vinyl IL monomer was synthesized with a vinyl group named 1-butyl-3-(4-vinylbenzyl)imidazolium 
chloride ([BVBI] $[\mathrm{Cl}])$ in order to prepare AEMs. After that, photocopolymerization of the $[\mathrm{BVBI}][\mathrm{Cl}]$ was performed in the presence of acrylonitrile and styrene as comonomers in order to synthesize AEMs. The physical, mechanical, and electrochemical properties of the synthesized AEMs were investigated for application to the CDP device membrane. Finally, the specific capacitance CDP device with the synthesized AEMs was determined by galvanostatic charge/discharge analysis and cyclic voltammetry analysis.

\section{Materials and Methods}

2.1. Materials. Styrene, acrylonitrile, 1-butylimidazole, 4vinylbenzyl chloride, and divinylbenzene were obtained from Sigma-Aldrich, USA. The acetonitrile, sodium chloride, sodium hydroxide, ammonia solution, and hydrochloric acid solution (Samchun, South Korea) and P12 (NEO Special, South Korea) were purchased. Before use, the acrylonitrile was distilled and the styrene and divinylbenzene were made inhibitor-free by passing the liquid through a column filled with $\mathrm{Al}_{2} \mathrm{O}_{3}$ powder.

2.2. Synthesis and Characterization of the [BVBI][Cl]. The vinylated ILs, [BVBI] [Cl], were synthesized by coupling reaction of 1-butylimidazole $(0.2 \mathrm{~mol}, 30 \mathrm{~mL})$ and 4-vinylbenzyl chloride $(0.2 \mathrm{~mol}, 39 \mathrm{~mL})$ in acetonitrile $(150 \mathrm{~mL})$ at $70^{\circ} \mathrm{C}$ for $16 \mathrm{~h}$ under nitrogen atmosphere. The resultants were washed using ether three times to remove acetonitrile and then the products were dried in a vacuum oven at room temperature for $6 \mathrm{~h}$ to remove ether. The chemical structure of the synthesized $[\mathrm{BVBI}][\mathrm{Cl}]$ with vinyl groups was confirmed by ${ }^{1} \mathrm{H}$ NMR spectroscopy (Inova 600, Varian, USA) and Fourier transform infrared spectroscopy (IS10 FT-IR, Thermo Scientific, USA).

2.3. Preparation of the AEMs. The AEMs were synthesized as follows: the mixture solution of the synthesized [BVBI][Cl] $(0.015 \mathrm{mmol}, 4 \mathrm{~g})$, styrene $(0.043 \mathrm{mmol}, 4.5 \mathrm{~g})$, acrylonitrile $(0.028 \mathrm{mmol}, 1.5 \mathrm{~g})$, divinylbenzene $(0.003 \mathrm{mmol}, 0.5 \mathrm{~g})$, and P12 (2.0 wt\% to feed) as a photoinitiator was stirred to obtain a homogeneous solution. The AEMs were prepared by photocopolymerization of the mixture solution on glass plate using irradiation with ultraviolet light of a $250 \sim 440 \mathrm{~nm}$ wavelength for $30 \mathrm{~min}$ at room temperature as shown in Figure 1.

2.4. Characterization of the AEMs. The chemical structure of the synthesized AEMs was confirmed by ${ }^{1} \mathrm{H}$ NMR spectroscopy (Inova 600, Vairan, USA) and Fourier transform infrared (FT-IR) spectroscopy (Is10 FT-IR spectrometer, Thermo Scientific, USA). The morphology of the prepared AEMs was also characterized by using a scanning electron microscope (FE-SEM (S-4800), Hitachi Science System, Japan).

The water uptake $W(\%)$ for the synthesized AEMs was calculated with the following equation:

$$
W(\%)=\frac{W_{w}-W_{d}}{W_{d}} \times 100 \%,
$$

where $W_{d}$ and $W_{w}$ are the weight of the dried and wetted AEMs immersed in deionized water at room temperature for $24 \mathrm{~h}$, respectively. Here, the wetted AEMs were treated by removing the excess water on the surface using tissue paper.

The swelling ratio (\%) for the AEMs was characterized by a linear expansion ratio, which was determined by the difference between the wet and dry dimensions of a membrane sample. The calculation was conducted with the following equation:

$$
\text { Swelling }(\%)=\frac{X_{\text {wet }}-X_{\text {dry }}}{X_{\text {dry }}} \times 100 \% \text {, }
$$

where $X_{\text {wet }}$ and $X_{\text {dry }}$ are the lengths of the wet state and dry state AEMs, respectively.

The ion exchange capacity (IEC) of the AEMs was determined via a back-titration method. The AEMs were dried and weighed before immersing them in a $0.01 \mathrm{M} \mathrm{NaOH}$ solution $(100 \mathrm{~mL})$ for $48 \mathrm{~h}$. The AEMs with hydroxide ions were again immersed in $0.01 \mathrm{M} \mathrm{HCl}$ solution for $48 \mathrm{~h}$. After anion exchange, the $\mathrm{HCl}$ solution was titrated by a $0.01 \mathrm{M}$ ammonia solution in the presence of phenolphthalein as an indicator. The IEC value was calculated as follows:

$$
\mathrm{IEC}=\frac{V_{0, \mathrm{HCl}} C_{\mathrm{HCl}}-V_{X, \mathrm{HCL}} C_{\mathrm{HCl}}}{m_{\mathrm{dry}}},
$$

where $V_{0, \mathrm{HCl}}$ and $V_{X, \mathrm{HCl}}$ are the volume of the consumed $\mathrm{HCl}$ without AEMs and with AEMs, respectively. $C_{\mathrm{HCl}}$ is the molar concentration of the $\mathrm{HCl}$, which is titrated by the $0.01 \mathrm{M}$ ammonia solution, and $m_{\mathrm{dry}}$ is the mass of the dry samples. Titration was performed three times.

The mechanical properties of the samples were measured by using an Instron universal tester (AG-X, Shimadzu, Japan) at room temperature, with $10 \mathrm{~mm} \times 25 \mathrm{~mm}$ at a crosshead speed of $25 \mathrm{~mm} / \mathrm{min}$. Tensile strength, tensile modulus, and elongation at break values were recorded.

The thermal stabilities of the synthesized samples were recorded by thermogravimetric analyzer (TGA N-1000, SCINCO, South Korea) under a nitrogen flow from 25 to $500^{\circ} \mathrm{C}$ at a heating rate of $10^{\circ} \mathrm{C} / \mathrm{min} r$.

The resistance value of the prepared AEMs was measured by four-point probe alternating current (AC) impedance spectroscopy (IM 6 EX, Zahner, German) with a frequency range of $1 \mathrm{~Hz}$ to $1 \mathrm{MHz}$. The ionic conductivity of the membrane, $\sigma(\mathrm{S} / \mathrm{cm})$, was calculated from the equation:

$$
\sigma=\frac{l}{R A},
$$

where $l$ is the distance between two platinum wire electrodes $(\mathrm{cm}), A$ is the cross-sectional area of sample $\left(\mathrm{cm}^{2}\right)$, and $R$ is the sample resistance value from the AC impedance data $(\Omega)$. The samples were fully hydrated in deionized water for $24 \mathrm{~h}$ for conductivity measurement. To maintain the relative humidity at $100 \%$ during the experiments, conductivity measurements were conducted in a chamber filled with deionized water under fully hydrated conditions. 


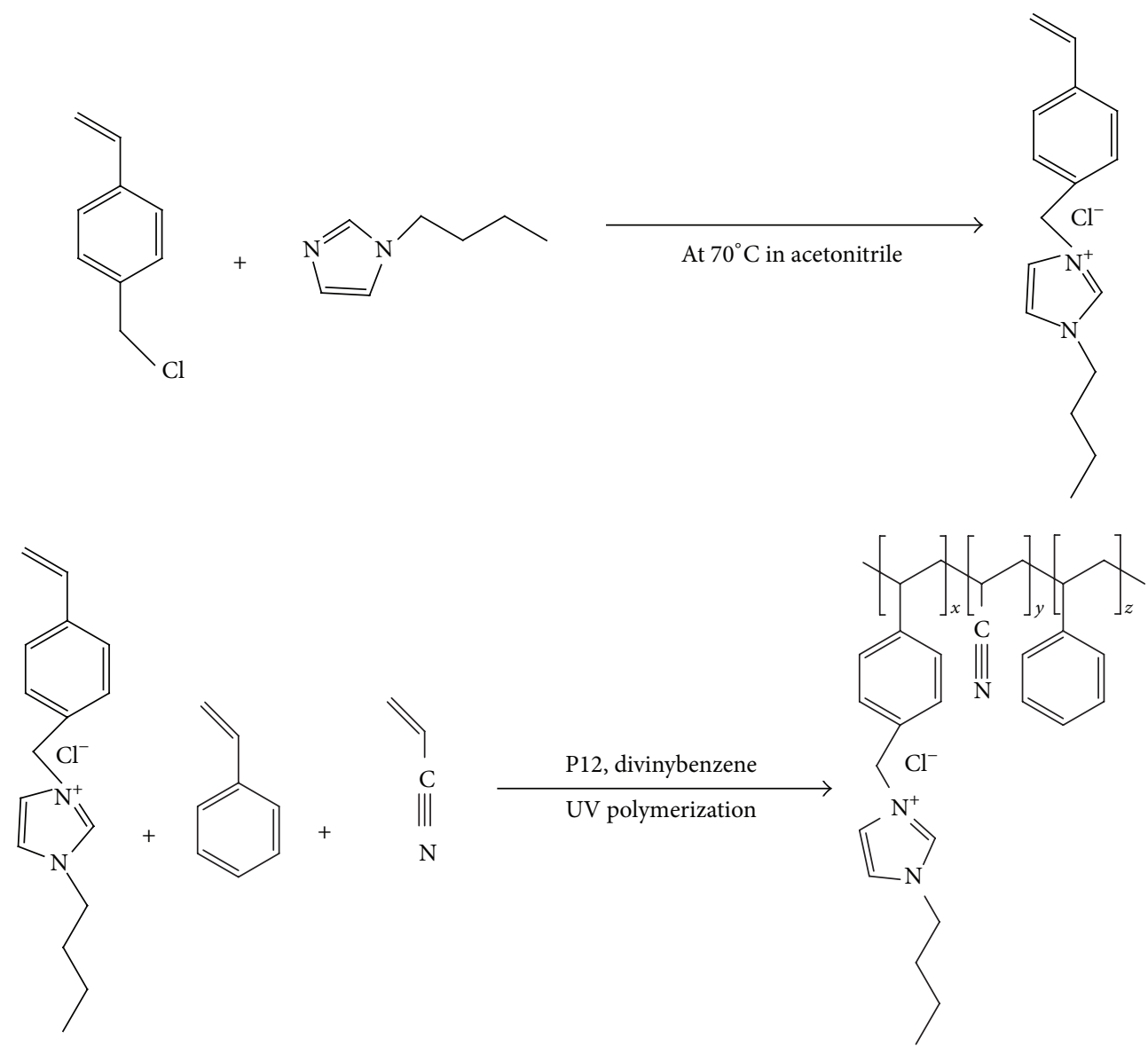

FIGURE 1: Synthesis of anion-exchange vinyl monomer and anion-exchange polymer by UV copolymerization.

2.5. Fabrication of CDP Device Flow System with AEMs. The CDP device flow system with a flow channel of $10 \mathrm{~cm} \times 2.2 \mathrm{~cm}$ $\times 1.5 \mathrm{~cm}$ was fabricated according to a homemade method (see Figure 7(a)). Graphite plates were used as current collectors (unique carbon, South Korea). Here, each current collector was introduced to an activated carbon electrode, which is prepared by coating of the activated carbon slurry with $10 \%$ nafion (Sigma-Aldrich, USA) on carbon paper. The surface area of the activated carbon electrode was calculated as $22 \mathrm{~cm}^{2}$. In detail, the carbon slurry was prepared by the mixing of the activated carbon powder $(2.0 \mathrm{~g})$ and $10 \%$ nafion $(2.0 \mathrm{~mL})$ in 2-propanol $(2.0 \mathrm{~mL})$ by magnetic stirring for $12 \mathrm{~h}$. The carbon slurry was casted by doctor blade on the surface of graphite paper (Wonatech, South Korea) and was then dried for $24 \mathrm{~h}$ at room temperature. The $0.5 \mathrm{M} \mathrm{NaCl}$ solution and a $0.017 \mathrm{M} \mathrm{NaCl}$ solution as an electrolyte were sequentially flowed in the CDP device at a $60 \mathrm{~mL} / \mathrm{min}$ flow rate.

The capacitance $(F)$ was investigated by the cyclic voltammetry and galvanostatic charge-discharge methods (Versa STAT-3, Ametek, USA). In detail, the cyclic voltammetry analysis of the CDP device was performed from $0.4 \mathrm{~V}$ to $-0.4 \mathrm{~V}$ with $1 \mathrm{mV} / \mathrm{s}$. The capacitance $(F)$ of the CDP device with AEMs was measured as the total integrating current value in a range of $0.0 \mathrm{~V} \sim+0.3 \mathrm{~V}$ from the obtained cyclic voltammograms.
Galvanostatic charge-discharge with a current density of $0.45 \mathrm{~A} / \mathrm{m}^{2}$ was also performed. The capacitance $(F)$ was calculated as in the following equation:

$$
C=\frac{Q}{\Delta V}
$$

where $C$ is the capacitance $(F), Q$ is the amount of charges $(C)$, and $\Delta V(V)$ is obtained from Galvanostatic charge-discharge data.

\section{Results and Discussion}

Figure 2 designates the Fourier transform infrared (FT-IR) spectra of the $[\mathrm{BVBI}][\mathrm{Cl}]$ as ionic liquids and the prepared AEMs. Both [BVBI] [Cl] and the AEMs displayed the characteristic peaks at $3000 \sim 3200 \mathrm{~cm}^{-1}$ and $1450 \sim 1600 \mathrm{~cm}^{-1}$ due to the aromatic ring in vinyl ionic liquids and AEMs. The characteristic peaks at $\sim 1578 \mathrm{~cm}^{-1}$ and $\sim 861 \mathrm{~cm}^{-1}$ were also displayed due to the imidazolium cations stretching band. The peaks of the cyano $(-\mathrm{C} \equiv \mathrm{N})$ group for the vinyl ionic liquids and AEMs were presented at $2248 \mathrm{~cm}^{-1}$ as strong stretching. As for results, the vinyl ionic liquids as vinyl monomers and AEMs were successfully synthesized.

Figure 3 shows the ${ }^{1} \mathrm{H}$ NMR spectra of the synthesized vinyl ionic liquids (Figure 3(a)) and AEMs prepared by 


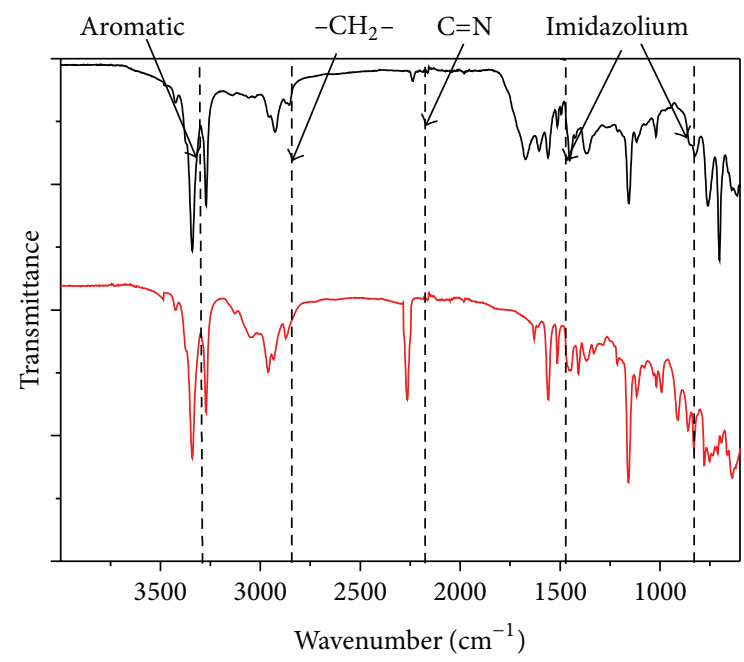

FIGURE 2: FT-IR spectra of [BVBI][Cl] (black line) and anionexchange membrane (red line).

photocopolymerization (Figure 3(b)). The structures of the $[\mathrm{BVBI}][\mathrm{Cl}]$ and AEMs were assigned as shown in Figure 3. From these results, it is clear that the AEMs for CDP device were successfully synthesized.

Figure 4 presents photograph (Figure 4(a)), of the surface SEM images (Figure 4(b)), and the cross-section SEM image (Figure 4(c)) for the AEM prepared photocopolymerization. The prepared AEM appeared as a transparent film and displayed uniform surface morphology as shown in Figures 4(a) and 4(b). The thickness of the prepared AEMs was determined to be about $26.1 \mu \mathrm{m}$ from the cross-section SEM images. In the cross-section SEM image of the AEM, the diversiform voids were presented due to solvent evaporation based on high temperature induced during photocopolymerization. However, visual observation was used to confirm that the prepared AEMs displayed good mechanical properties before they were used as a CDP device membrane.

Figure 5 displays thermogravimetric analysis (TGA) curves (Figure 5(a)) and an impedance plot (Figure 5(b)) of AEM prepared by photocopolymerization. In Figure 5(a), the first weight loss for the AEM was displayed during $250^{\circ} \mathrm{C} \sim$ $450^{\circ} \mathrm{C}$ due to copolymer main degradation. These results mean the synthesized AEM displayed high thermal stability. The electrical resistance of the SEM was $9.47 \times 10^{3} \Omega$ as shown in Figure 5(b). The ion conductivity of the AEM was calculated to be $3.05 \times 10^{-3} \mathrm{~S} / \mathrm{cm}$. As for results, the prepared AEM could be applied as an anionic-exchanged membrane in a CDP device flow system.

Table 1 summarizes the physical, mechanical, and electrochemical properties of the synthesized AEM. The water uptake (\%) and swelling degree of the AEM were $66.0 \%$ and $27.8 \%$, respectively. Tensile strength, tensile modulus, and elongation at the break of the prepared AEM were calculated to be $13.3 \mathrm{Mpa}, 330.3 \mathrm{Mpa}$, and $42.6 \%$, respectively. The ion exchange capacity (IEC) of the prepared AEM can be refracted from the exchangeable properties. The IEC value of the AEM was $0.499 \mathrm{mmol} / \mathrm{g}$, and this value was close to the

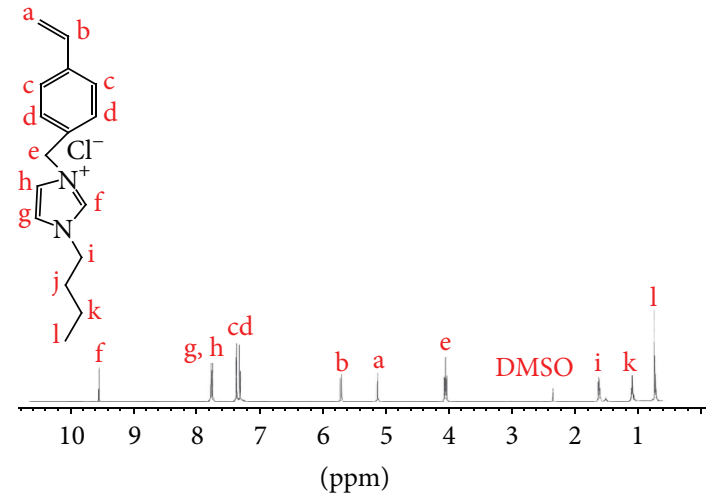

(a)

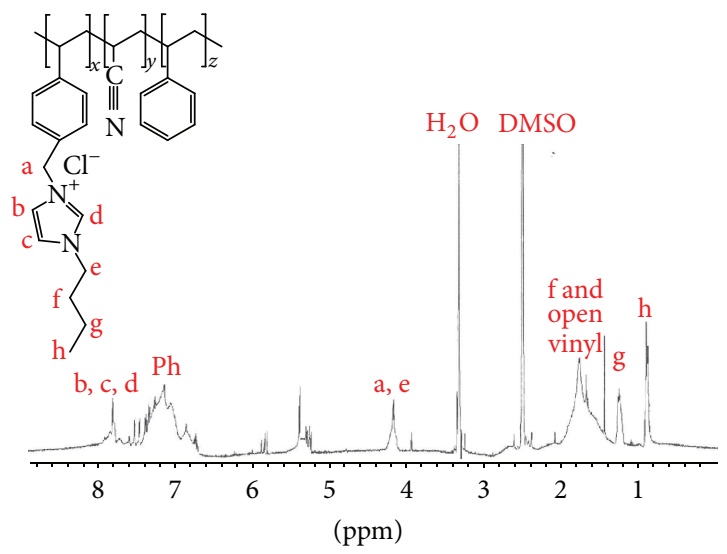

(b)

FIGURE 3: ${ }^{1} \mathrm{H}$ NMR spectra of the synthesized vinyl ILs (a) and AEMs prepared by photocopolymerization (b).

theoretical value $(0.567 \mathrm{mmol} / \mathrm{g})$. As for results, the prepared AEMs can be used as separators in CDP device flow systems.

Figure 6 displays a photograph of the CDP device flow system with AEMs (Figure 6(a)) and cell potential (mV) and power density $\left(\mathrm{mW} / \mathrm{m}^{2}\right)$ according to time (Figure $6(\mathrm{~b})$ ) for $0.5 \mathrm{M} \mathrm{NaCl}$ electrolyte flow as charging and $0.015 \mathrm{M}$ $\mathrm{NaCl}$ electrolyte flow as discharging. In CDP flow system performance, the $0.5 \mathrm{M} \mathrm{NaCl}$ electrolyte first flowed through the CDP flow device as a charging step related to linear cell potential. In this study, the linear cell potential $(\sim 18 \mathrm{mV})$ of the CDP device with AEM was reached at time of $1000 \mathrm{~s}$. This means that ions flowed through the anion-exchange membranes to the capacitive electrodes. The Donnan potential occurred in the CDP device with AEM from ion flow to the capacitive electrode as cell potential. In this CDP device with AEM performance, the highest power density obtained was calculated at $109.0 \mathrm{~mW} / \mathrm{m}^{2}$ as charging step and $20 \mathrm{~mW} / \mathrm{m}^{2}$ as discharging step, respectively. As for the results, energy extraction from the CDP device flow system with AEM could be obtained according to the salinity gradients.

Figure 7 displays cyclic voltammograms with a $1.0 \mathrm{mV} / \mathrm{s}$ scan rate (Figure 7(a)) and the galvanostatic charge and discharge (Figure $7(\mathrm{~b})$ ) of the CDP device flow system with $0.45 \mathrm{~A} / \mathrm{m}^{2}$ current density at a $60 \mathrm{~mL} / \mathrm{min}$ flow rate. In 


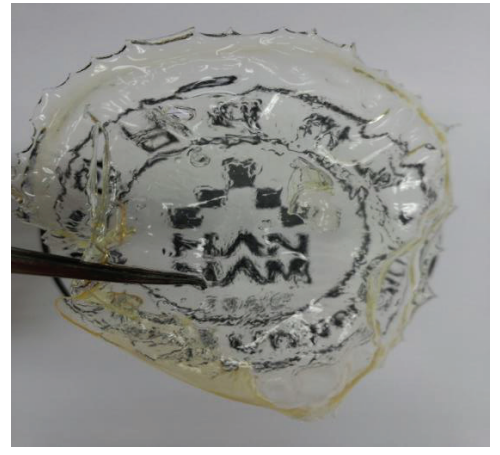

(a)

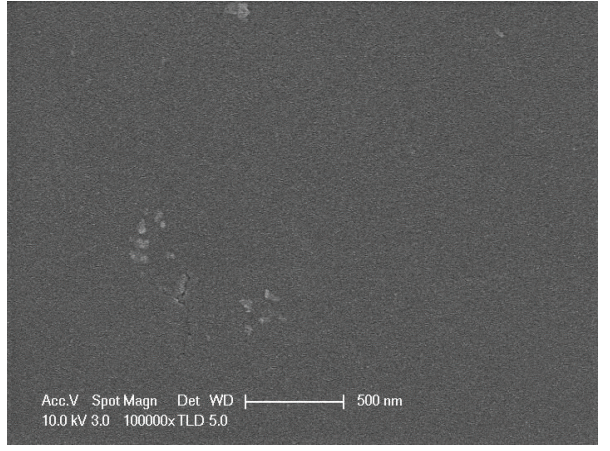

(b)

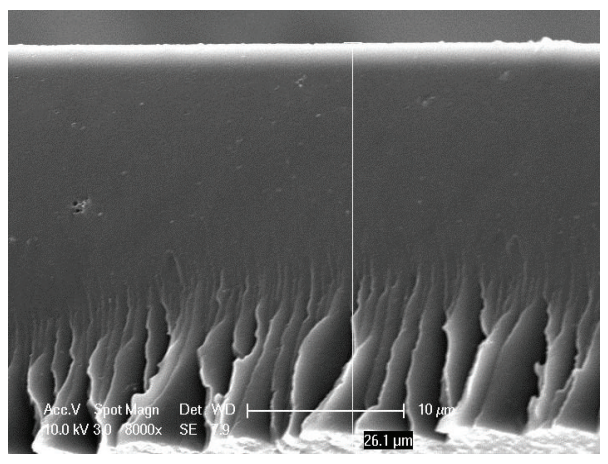

(c)

FIGURE 4: Photograph (a), the surface SEM images (b), and cross-section SEM image (c) for the AEM prepared photocopolymerization.

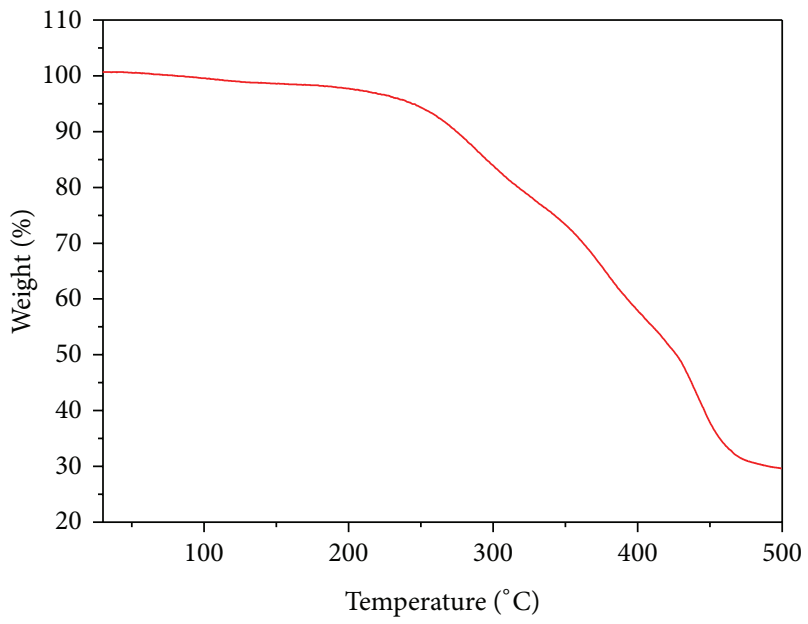

(a)

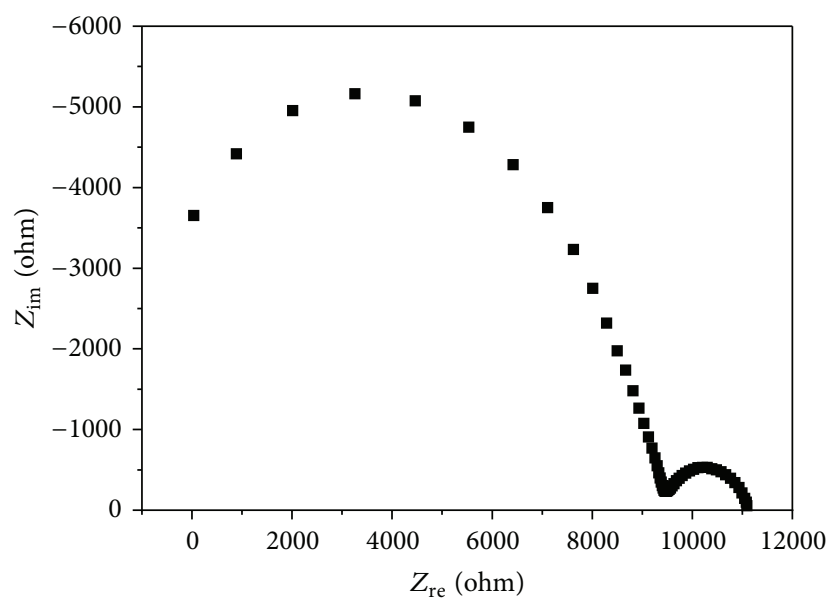

(b)

FIGURE 5: Thermogravimetric analysis (TGA) curves (a) and an impedance plot (b) of AEM prepared by photocopolymerization.

TABLE 1: Physical, mechanical, and electrochemical properties of the synthesized AEMs.

\begin{tabular}{|c|c|c|c|c|c|c|c|c|}
\hline & \multicolumn{2}{|c|}{ Physical properties } & \multicolumn{3}{|c|}{ Mechanical properties } & \multicolumn{3}{|c|}{ Electrochemical properties } \\
\hline & \multirow{2}{*}{$\begin{array}{l}\text { Water uptake } \\
(\%)\end{array}$} & \multirow{2}{*}{$\begin{array}{l}\text { Swelling ratio } \\
(\%)\end{array}$} & \multirow{2}{*}{$\begin{array}{l}\text { Tensile } \\
\text { strength (Mpa) }\end{array}$} & \multirow{2}{*}{$\begin{array}{l}\text { Tensile } \\
\text { modulus } \\
\text { (Mpa) }\end{array}$} & \multirow{2}{*}{$\begin{array}{l}\text { Elongation at } \\
\text { break }(\%)\end{array}$} & \multirow{2}{*}{$\begin{array}{l}\text { Ion conductivity } \\
(\mathrm{S} / \mathrm{cm})\end{array}$} & \multicolumn{2}{|c|}{$\begin{array}{c}\text { Ion exchange capacity } \\
(\mathrm{mmol} / \mathrm{g})\end{array}$} \\
\hline & & & & & & & Theoretical & Experimental \\
\hline$\overline{\mathrm{AEM}}$ & 66.0 & 27.8 & $13.3 \pm 2.1$ & $330.3 \pm 24.1$ & $42.6 \pm 7.7$ & $3.05 \times 10^{-3}$ & 0.567 & 0.499 \\
\hline
\end{tabular}



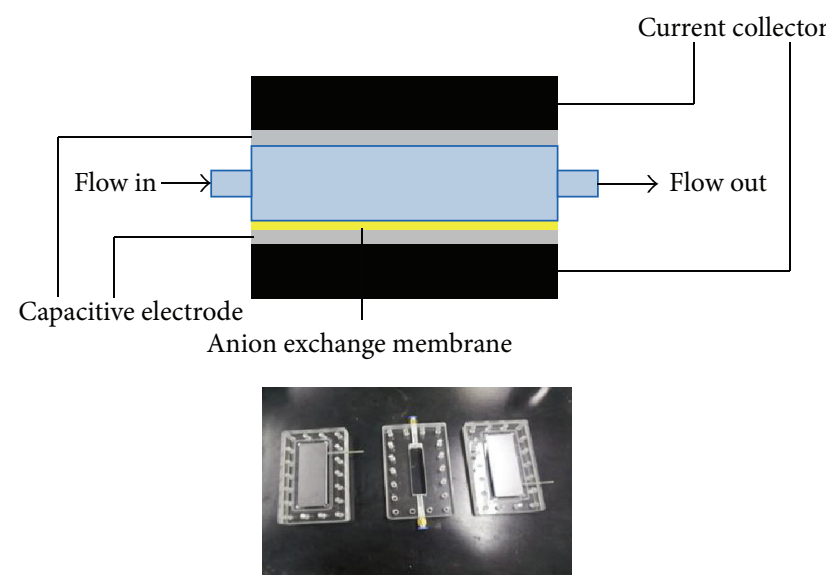

(a)

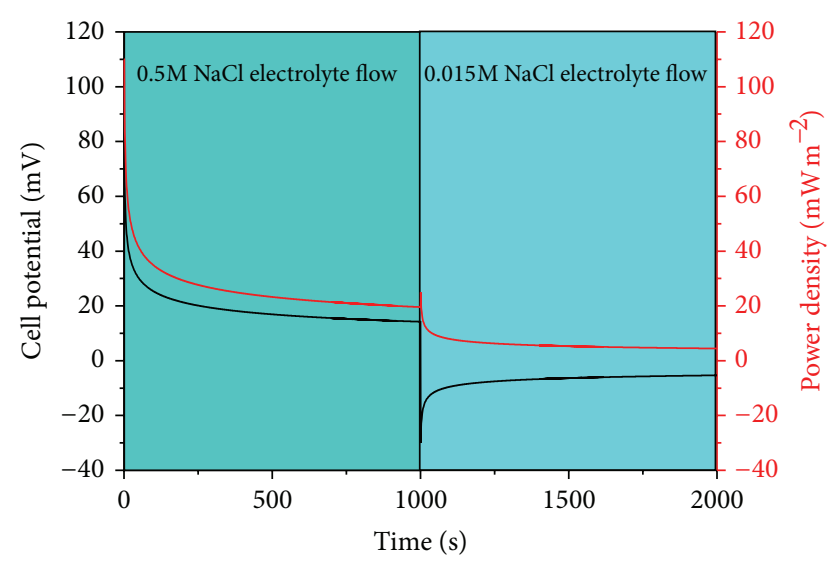

(b)

FIGURE 6: Photograph of the CDP device flow system with AEMs (a) and cell potential (mV) and power density $\left(\mathrm{mW} / \mathrm{m}^{2}\right)$ according to time (b) for $0.5 \mathrm{M} \mathrm{NaCl}$ electrolyte flow as charging and $0.015 \mathrm{M} \mathrm{NaCl}$ electrolyte flow as discharging.

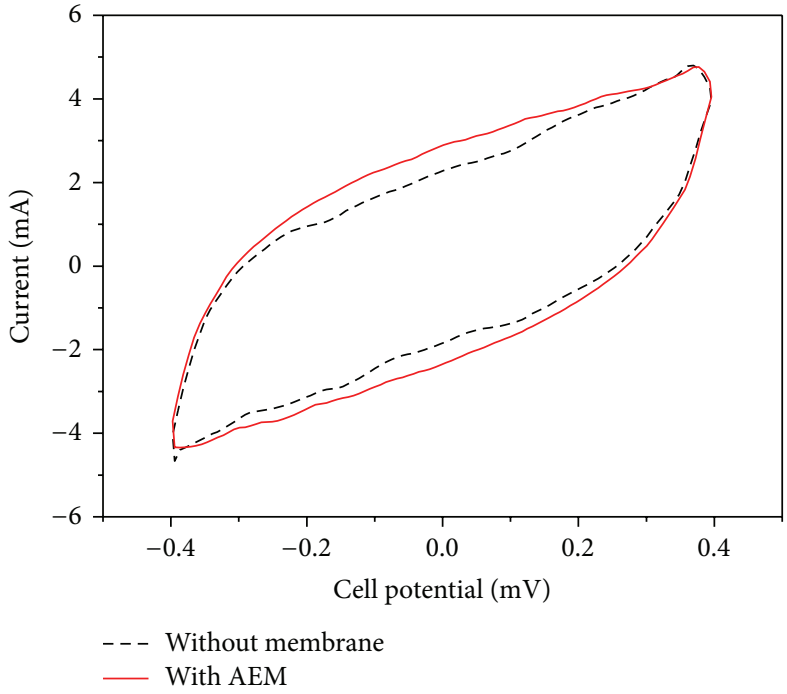

(a)

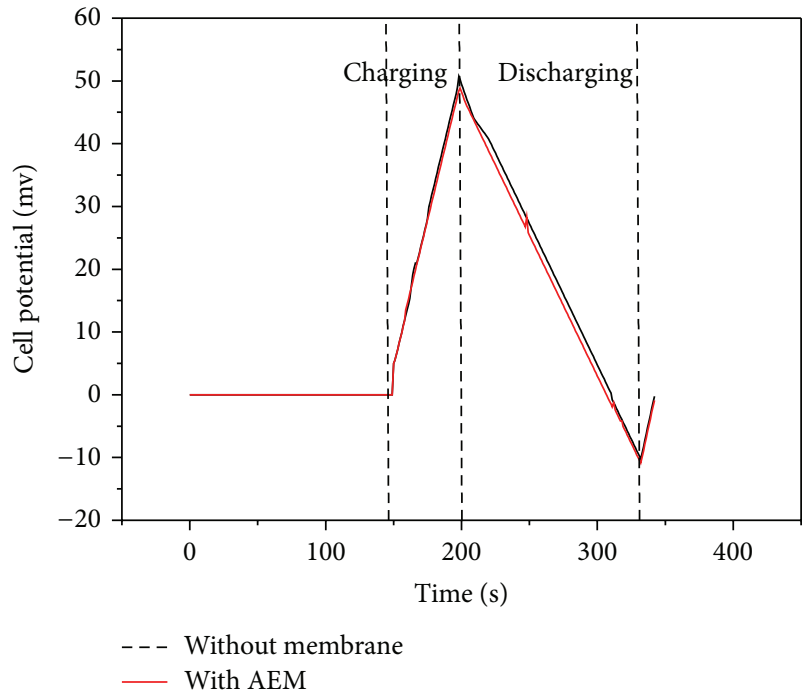

(b)

FIGURE 7: Cyclic voltammograms with $1.0 \mathrm{mV} / \mathrm{s}$ scan rate (a) and galvanostatic charge and discharge (b) with $0.45 \mathrm{~A} / \mathrm{m}^{2}$ current density of CDP device flow system at a $60 \mathrm{~mL} / \mathrm{min}$ flow rate.

Figure 7(a), the specific capacitances of the CDP device with AEM and without AEM were calculated at $3.44 \mathrm{~F} / \mathrm{g}$ and $2.93 \mathrm{~F} / \mathrm{g}$, respectively. In Figure 7(b), the specific capacitances of the CDP device with AEM were also determined to be at $2.53 \mathrm{~F} / \mathrm{g}$ and $2.20 \mathrm{~F} / \mathrm{g}$ as charging and discharging, respectively. The specific capacitances of the CDP device without AEM were also determined to be $2.41 \mathrm{~F} / \mathrm{g}$ and $2.17 \mathrm{~F} / \mathrm{g}$ as charging and discharging, respectively. As for the results, the specific capacitance of the CDP device with AEM was higher than that of the CDP device without AEM. The prepared AEMs can be used as a separator in CDP device flow systems.

Table 2 summarizes the specific capacitances (F/g) of a CDP device flow system with a $60 \mathrm{~mL} / \mathrm{min}$ flow rate in $0.5 \mathrm{M}$
$\mathrm{NaCl}$ electrolyte in the presence and absence of AEM. The specific capacitance of the CDP device flow system with AEM was higher than that of the CDP device flow system without AEM by $\mathrm{CV}$ and galvanostatic charge and discharge measurement. From these results, the synthesized AEM can be applied as a separator in CDP device flow systems.

\section{Conclusions}

The AEMs were synthesized via the photocopolymerization of vinyl imidazolium ionic liquid, [BVBI][Cl] as anionexchange group, styrene, acrylonitrile, and divinylbenzene as cross-linked agents. The synthesized AEMs were characterized with physical, mechanical, and electrochemical 
TABLE 2: Specific capacitances (F/g) of the CDP device flow system with a $60 \mathrm{~mL} / \mathrm{min}$ flow rate in $0.5 \mathrm{M} \mathrm{NaCl}$ electrolyte in the presence and absence of AEM.

\begin{tabular}{|c|c|c|c|}
\hline & \multicolumn{2}{|c|}{ Galvanostatic charge-discharge $\mathrm{a}^{\mathrm{a}}$} & \multirow{2}{*}{$\begin{array}{c}\text { Cyclic } \\
\text { voltammetry }^{\mathrm{b}}\end{array}$} \\
\hline & Charge (F/g) & $\begin{array}{l}\text { Discharge } \\
(\mathrm{F} / \mathrm{g})\end{array}$ & \\
\hline Without AEM & 2.41 & 2.17 & 2.41 \\
\hline With AEM & 2.53 & 2.20 & 3.44 \\
\hline
\end{tabular}

${ }^{a}$ At a $0.45 \mathrm{~A} / \mathrm{m}^{2}$ current density.

${ }^{\mathrm{b}}$ At a $1 \mathrm{mV} / \mathrm{s}$ scan rate.

properties in order to be used as membranes in CDP devices. As a result, the conclusions are as follows.

(1) Water uptake (66.0\%), swelling degree (27.8\%), tensile strength (13.3 Mpa), tensile modulus (330.3 Mpa), elongation at break (42.6\%), ion conductivity $\left(3.05 \times 10^{-3} \mathrm{~S} / \mathrm{cm}\right)$, and ion exchange capacity $(0.499 \mathrm{mmol} / \mathrm{g})$ for the AEMs were evaluated.

(2) The specific capacitance of a CDP device flow system with AEMs was calculated at $3.44 \mathrm{~F} / \mathrm{g}$ by $\mathrm{CV}$ analysis and at $2.53 \mathrm{~F} / \mathrm{g}$ by galvanostatic charge-discharge analysis, respectively.

(3) That synthesized AEM can be applied as a separator in CDP device flow systems.

\section{Conflict of Interests}

The authors declare that there is no conflict of interests regarding the publication of this paper.

\section{Acknowledgment}

This work was supported by National Research Foundation of Korea Grant funded by the South Korean government (NRF2013M1A3A3A02041878).

\section{References}

[1] E. S. Dragan, E. Avram, D. Axente, and C. Marcu, "Ion-exchange resins. III. functionalization-morphology correlations in the synthesis of some macroporous, strong basic anion exchangers and uranium-sorption properties evaluation," Journal of Polymer Science A: Polymer Chemistry, vol. 42, no. 10, pp. 2451-2461, 2004.

[2] A. K. Salem, F. R. A. J. Rose, R. O. C. Oreffo et al., "Porous polymer and cell composites that self-assemble in situ," Advanced Materials, vol. 15, no. 3, pp. 210-213, 2003.

[3] X. Jiang, H. Yu, R. Frayne, O. Unal, and C. M. Strother, "Surface functionalization of polyethylene for magnetic resonance signal-enhancing coating materials," Chemistry of Materials, vol. 14, no. 5, pp. 1914-1920, 2002.

[4] J. R. Varcoe and R. C. T. Slade, "Prospects for alkaline anionexchange membranes in low temperature fuel cells," Fuel Cells, vol. 5, no. 2, pp. 187-200, 2005.

[5] A. R. Roudman and R. P. Kusy, "UV-visible spectroscopic study of the reaction kinetics of methylpiperazine-modified poly(vinyl chloride)s for use as fixed-state proton carrier membranes," Polymer, vol. 39, no. 16, pp. 3641-3649, 1998.

[6] T. Xu, Z. Liu, and W. Yang, "Fundamental studies of a new series of anion exchange membranes: membrane prepared from poly(2,6-dimethyl-1,4-phenylene oxide) (PPO) and triethylamine," Journal of Membrane Science, vol. 249, no. 1-2, pp. 183-191, 2005.

[7] R. C. T. Slade and J. R. Varcoe, "Investigations of conductivity in FEP-based radiation-grafted alkaline anion-exchange membranes," Solid State Ionics, vol. 176, no. 5-6, pp. 585-597, 2005.

[8] J. Wang, Z. Zhao, F. Gong, S. Li, and S. Zhang, "Synthesis of soluble poly(arylene ether sulfone) ionomers with pendant quaternary ammonium groups for anion exchange membranes," Macromolecules, vol. 42, no. 22, pp. 8711-8717, 2009.

[9] S. Lu, J. Pan, A. Huang, L. Zhuang, and J. Lu, "Alkaline polymer electrolyte fuel cells completely free from noble metal catalysts," Proceedings of the National Academy of Sciences of the United States of America, vol. 105, no. 52, pp. 20611-20614, 2008.

[10] Y. Wang, L. Li, L. Hu, L. Zhuang, J. Lu, and B. Xu, "A feasibility analysis for alkaline membrane direct methanol fuel cell: thermodynamic disadvantages versus kinetic advantages," Electrochemistry Communications, vol. 5, no. 8, pp. 662-666, 2003.

[11] G. F. McLean, T. Niet, S. Prince-Richard, and N. Djilali, "An assessment of alkaline fuel cell technology," International Journal of Hydrogen Energy, vol. 27, no. 5, pp. 507-526, 2002.

[12] D. Brogioli, R. Zhao, and P. M. Biesheuvel, "A prototype cell for extracting energy from a water salinity difference by means of double layer expansion in nanoporous carbon electrodes," Energy and Environmental Science, vol. 4, no. 3, pp. 772-777, 2011.

[13] B. B. Sales, F. Liu, O. Schaetzle, C. J. N. Buisman, and H. V. M. Hamelers, "Electrochemical characterization of a supercapacitor flow cell for power production from salinity gradients," Electrochimica Acta, vol. 86, pp. 298-304, 2012. 

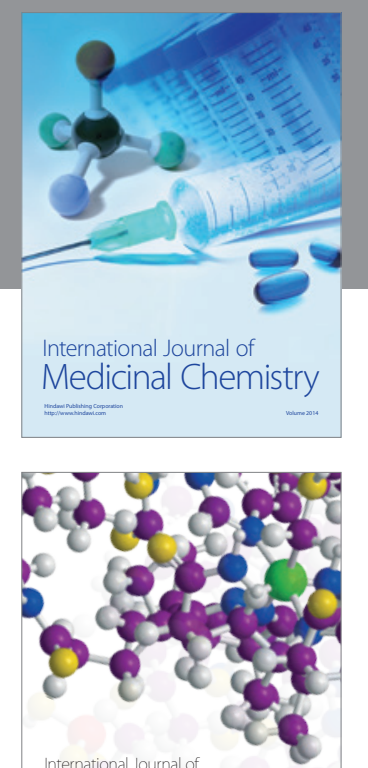

\section{Carbohydrate} Chemistry

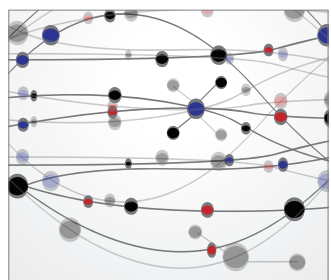

The Scientific World Journal
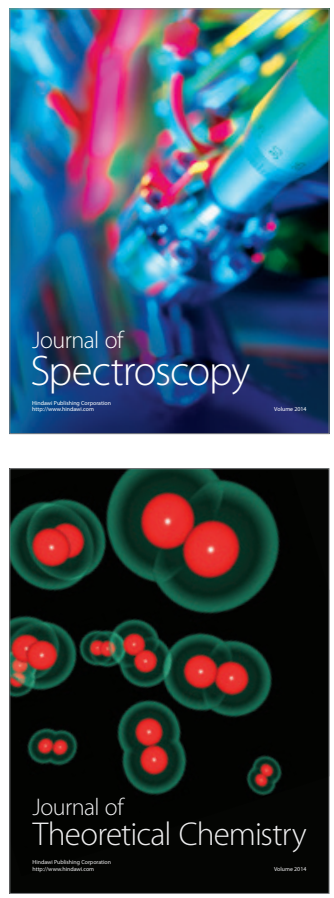
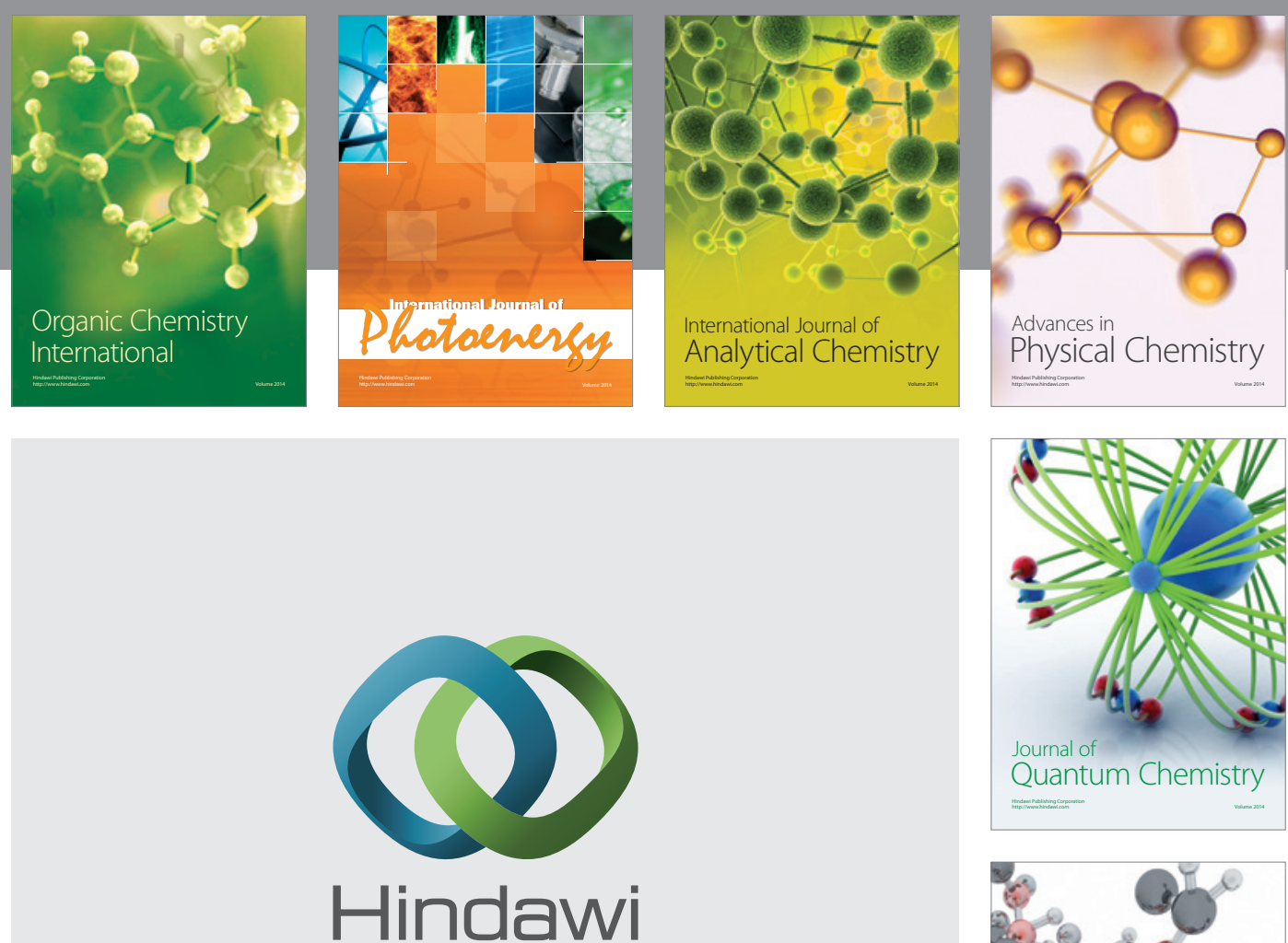

Submit your manuscripts at

http://www.hindawi.com

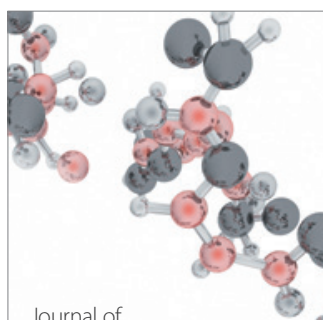

Analytical Methods

in Chemistry

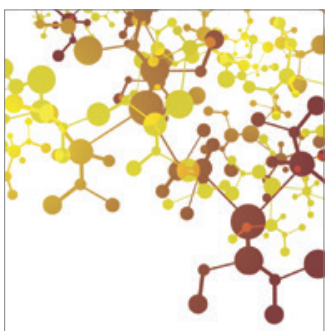

Journal of

Applied Chemistry

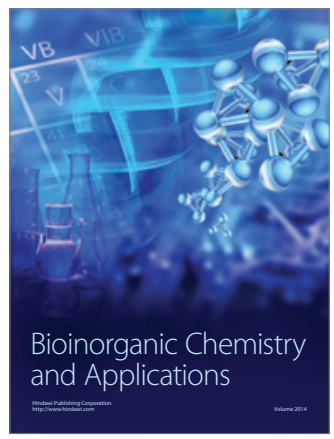

Inorganic Chemistry
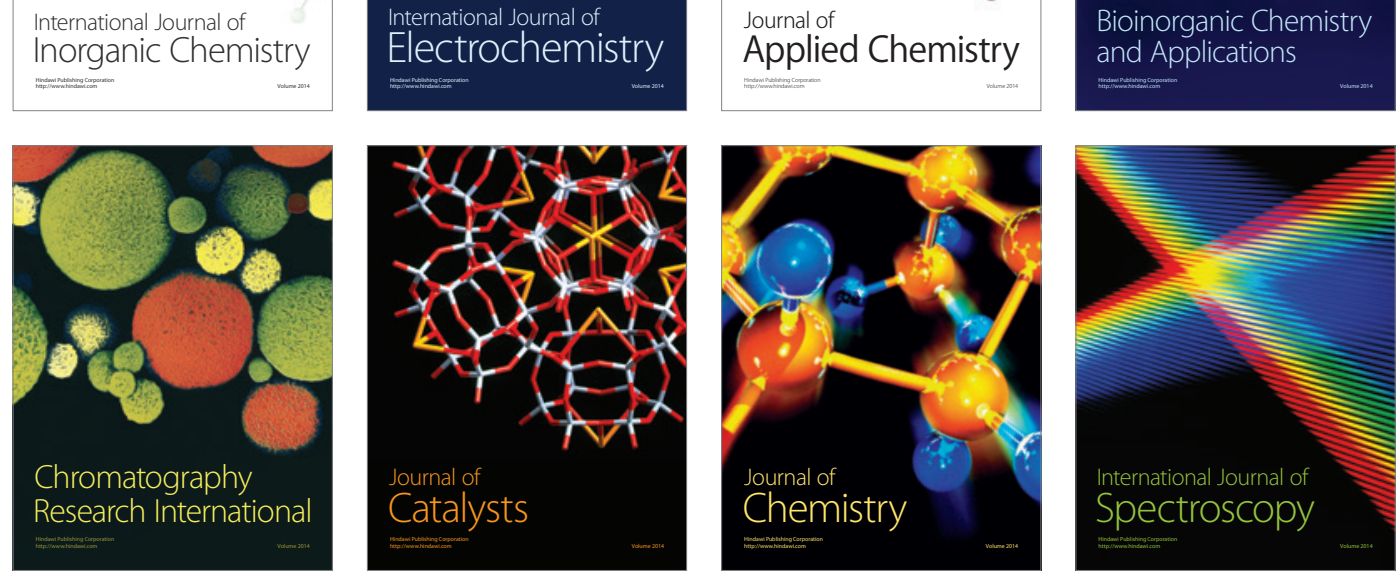